\title{
Comparative Study and Simulation of Soil Infiltration Performance in Open Green Space
}

\author{
Yu ZHANG, Fucun CAO, Leichang HUANG, Yunwei ZHOU, Zhao YANG
}

\begin{abstract}
Soil infiltration is important for urban open space to exert sponge benefits, and its permeability characteristics are influenced by physical and chemical properties. To determine the characteristics and differences of soil permeability in different open spaces, we used the cutting-ring method to measure the soil infiltration process in four types of open space. The effects of physicochemical properties on soil infiltration were analyzed through comparison. The infiltration process of the four types of green spaces was fitted on the basis of Kostiakov and Philip infiltration models, and the suitability of the models was discussed. The water infiltration process shows that the law of initial infiltration rate $>$ average infiltration rate > stable infiltration rate. The stable infiltration rate of each green space ranges from $2.46 \mathrm{~mm} / \mathrm{min}$ to $3.60 \mathrm{~mm} / \mathrm{min}$, and the ranking is as follows: park > square > block > other shared space. The determination coefficient of the Kostiakov model for the soil infiltration process of the four types of green space is higher than 0.94 , which is suitable to describe the soil infiltration characteristics of green space in the study area. The soil infiltration performance of green space shows a negative correlation with soil bulk density and moisture content but a positive correlation with non-capillary porosity. This study provides a reference for the construction of sponge cities and ecological hydrological observation.
\end{abstract}

Keywords: infiltration model; influencing factors; open space; soil in green space; water infiltration

\section{INTRODUCTION}

Urban open space is a space entity with natural biological activity and regeneration mechanism in an urban ecosystem [1]. It plays an increasingly important role in ecological services and restoration, social relation integration, land and space value, and culture expression. This entity is an important link in the coordinated development of urban space and ecosystem. With the continuous development of sponge city construction, green space is an important part of underlying surface in urban open space, and its natural infiltration regulation function plays a key role in absorbing rain and flood [2, 3].

Green space achieves the functions of runoff regulation and water retention through soil infiltration. Soil permeability is an important indicator and parameter for the evaluation of hydrological effects [4]. Soil with good permeability can absorb rainwater and has sufficiently high surface runoff control rate to conserve and effectively use rainwater resources, thereby achieving the sponge effect of urban green space. However, the principle and influencing factors of soil infiltration in urban construction remain widely unknown. Important indicators of soil infiltration are neglected in design and construction, thereby causing a bottleneck to sponge city construction.

In recent years, the soil water retention performance, infiltration parameters, and reservoir characteristics of green land have been extensively studied [5-7]. However, the infiltration characteristics of green space and the coupling relation of influencing factors and the selection and fitting comparison of infiltration models are rarely evaluated. Therefore, the soil infiltration characteristics of different open spaces must be urgently quantitatively evaluated, compared, and simulated to clarify the infiltration process and to determine the coupling relation of influencing factors.

Based on the above analysis, this study examines the soil infiltration process of green space and the suitability of the infiltration model. Subsequently, the coupling relations of influencing factors are also considered.

\section{STATE OF THE ART}

Soil infiltration performance has been extensively studied. Regarding soil infiltration measurement, Lai \& Ren [8] used the simple and time-saving double-ring method to measure the physical and chemical properties of surface soil. However, the double-ring diameter affects the infiltration measurement results. Joel et al. [9-11] adopted various portable and rotating rainfall simulators to simulate natural rainfall and study soil infiltration in forest land. They focused on the accuracy of infiltration results but did not discuss the influencing factors of soil infiltration. Regarding the influencing factors of soil infiltration, Minh et al. $[12,13]$ tested the physical and chemical properties of the different types of soil with different depths and determined that soil texture, bulk density, structure, and organic matter content have significant influence on soil infiltration. However, none of them conducted actual studies of urban green space. To reveal the soil infiltration performance of green space, Gill et al. [14] conducted a simulation in Greater Manchester and found that a $10 \%$ increase in green space coverage in residential areas can reduce surface runoff by $4.9 \%$, and increasing $10 \%$ similar green space coverage can decrease surface runoff by $5.7 \%$. This finding showed the effective control of soil infiltration over surface runoff. However, he did not explore the soil infiltration performance of the different types of green land. By studying the two cases of green infrastructures in Northwest England, Carter et al. [15] determined that green soil can effectively control flood risk. The infiltration performance of green land is directly related to the migration and accumulation of rainfall and irrigation water in soil. Infiltration significantly affects surface runoff and flood management. In recent years, digital technology has been continuously updated, and infiltration models have become widely used to study soil infiltration performance. Common infiltration models include Kostiakov, GreenAmpt, Philip, Horton, Collis-George et al. [16]. Ma et al. [17] used the above mentioned models to describe the soil infiltration process of parks in Kunming, China and found that the infiltration performance of arbor-shrub-grass green land is better than that of arbor-grass green land and shrub- 
grass green land. Furthermore, soil in reconstructed parks in natural green space has better infiltration performance than that in artificial vegetation. However, he focused only on green land in parks. Xiong [4] measured soil permeability and quantitatively analyzed the five types of green space in Shenzhen. The Kostiakov model was used to fit the water infiltration process. However, he did not compare the differences between various models. To comprehensively evaluate the soil permeability of green space in different regions, Dai et al. [2] used a Guelph infiltration meter to study the infiltration characteristics of soil in the five types of green land in Beijing. However, he did not conduct model verification. Wu et al. [18-20] studied the distribution rules and influencing factors of the soil infiltration of green land in functional areas in Shanghai and found that concave green land has better retention and infiltration effects than flat green land. Zhang \&Wang [21] analyzed the texture and type of soil in 34 green lands in Xinxiang and found that the complex vertical structure and soil layer distribution of green lands are also important factors that influence soil infiltration. The results provide a reference for thoroughly studying infiltration performance.

The abovementioned studies focused on a single aspect, such as soil infiltration measurement methods, green space infiltration influencing factors, and infiltration model parameter determination. However, comparative studies on soil infiltration characteristics of different types of green space, particularly the coupling relationship of influencing factors, and the comparison between the actual measurement and model fitting have been rarely conducted. Based on the influencing factors of physical and chemical properties of soil, this study conducts the methods of cutting-ring and model-fitting comparison to analyze the infiltration laws and the differences of the four types of open green space. Kostiakov \& Philip infiltration model fitting curves are established. Moreover, the coupling relations of the factors influencing infiltration performance and the suitability of the models are discussed, thereby providing a basis for predicting and optimizing the water retention and infiltration function of open green space.

The remainder of this study is structured as follows. Section 3 describes the setting and sampling of the sampling site, detection method, data statistics, and analysis methods. Section 4 compares and analyzes the four types of open space, the physical and chemical properties of soil, infiltration process and characteristics, the curve fitting of two infiltration models, and the correlation of soil infiltration factors. The differences and laws of the infiltration performance of the different types of open space are obtained. Finally, a summary and the conclusions are presented in Section 5.

\section{METHODOLOGY}

\subsection{Introduction to the Study Area and Plot Setting}

This study explores the open space in the core urban area of Dalian in Liaoning Province in Northeast China. Dalian is located in the southern part of the Liaodong Peninsula at $38^{\circ} 43^{\prime}-40^{\circ} 12^{\prime}$ North latitude and $120^{\circ} 58^{\prime}$ $123^{\circ} 31^{\prime}$ East longitude. The core urban area is approximately 62017 hectares. As of September 2018, the total area of open space in the core urban area of Dalian is approximately 11600 hectares, with an average vegetation coverage rate of $71.83 \%$. Referring to the generic types of open spaces in many countries, and combination of use function and land use nature, the open space of the core urban area in Dalian is divided into four types, namely, park, square, block, and other shared space. The green spaces in representative locations are sampled based on the number of typical sample spaces and types of vegetation. Except for shared spaces with evident dead leaves, such as some parks and roads, other green spaces are artificial communities. The understory is lawn. The basic information about the four types of green spaces is listed in Tab. 1.

Table 1 Types and characteristics of green spaces in the sample plot

\begin{tabular}{|c|c|c|c|c|}
\hline Type & Typical plot & Total number & Sampling point & Typical vegetation type \\
\hline Park & $\begin{array}{c}\text { Comprehensive park, Community park, } \\
\text { Specialized park, Various amusement park }\end{array}$ & 85 & 20 & $\begin{array}{c}\text { Arbor-shrub-grass, Arbor-grass, } \\
\text { Shrub-grass, Grassland }\end{array}$ \\
\hline Square & $\begin{array}{c}\text { Various leisure, Gathering and sports venue, } \\
\text { Parking lot }\end{array}$ & 73 & 15 & Arbor-grass, Shrub-grass, Grassland \\
\hline Block & $\begin{array}{c}\text { Commercial block, Historic block, Shared street } \\
\text { space }\end{array}$ & 21 & 10 & Shrub-grass, Grassland \\
\hline Other shared space & $\begin{array}{c}\text { Attached green space, Green road, Landscape } \\
\text { forest belt, Characteristic recreation area }\end{array}$ & 604 & 20 & $\begin{array}{c}\text { Arbor-shrub-grass, Arbor-grass, } \\
\text { Shrub-grass, Grassland }\end{array}$ \\
\hline
\end{tabular}

\subsection{Sampling and Infiltration Monitoring Methods}

In the four types of open space plots, 5 sample points were selected of each vegetation, a total of 60 sampling points were arranged at typical vegetation. Approximately 0-20 cm - deep soil layers were randomly selected at each sampling point. Two original soil samples were collected with a cutting ring $\left(5.1 \mathrm{~cm}\right.$ high, $\left.100 \mathrm{~cm}^{3}\right)$ from each layer and brought to the laboratory to measure and analyze the physicochemical properties and the infiltration performance.

The bulk density, porosity, and water capacity of the soil were measured by the cutting-ring method, whereas the moisture content was determined by the drying method. The average value of 3 replicate samples was taken for each layer. The infiltration rate was measured on the basis of the cutting-ring method. The upper and lower covers of a sample were removed, and the cutting ring was covered with an empty ring. Water was added to the empty cutting ring, and the water surface was maintained $1 \mathrm{~mm}$ lower than the upper edge. The thickness of the water layer was maintained at $5 \mathrm{~cm}$.

When the water penetrated the lower ring and the first drop of water seeped out of the soil, the test timing started. The time sequences during the entire test were 1, 2, 3, 4, 5, 10,15 and $20 \mathrm{~min}$ and so on. In the test, water should be added to the upper ring in time to keep the height of water surface at $5 \mathrm{~cm}$, and the beaker was replaced every time 
sequence. The test was continued until the steady state, that is, water was replaced in the beakers thrice at the same amount. The test of soil infiltration process was repeated thrice for each plot.

Infiltration rate and infiltration coefficient are calculated as follows:

$$
V=\frac{10 \cdot Q_{n}}{t_{n} \cdot S}
$$

where $V$ is the infiltration rate, $\mathrm{mm} / \mathrm{min} ; t_{n}$ is the time interval in each infiltration, min; $Q_{n}$ is the amount of permeated water during the time interval, $\mathrm{ml} . S$ is the crosssectional area of the cutting ring, $\mathrm{cm}^{2}$ and 10 is the multiple when converting $\mathrm{cm}$ to $\mathrm{mm}$.

The infiltration coefficient is calculated using the Darcy. $H$ model, and the formula is as follows:

$$
K_{t}=V \cdot \frac{L}{H+L}
$$

where $K_{t}$ is the infiltration coefficient at $t\left({ }^{\circ} \mathrm{C}\right), \mathrm{mm} / \mathrm{min} ; H$ is the thickness of the water layer, $\mathrm{cm}$; and $L$ is the thickness of the soil layer, $\mathrm{cm}$.

\subsection{Data Statistics and Analysis}

Infiltration performance is a physical characteristic parameter used to describe the speed of soil infiltration. Generally, the infiltration performance is described in accordance with four infiltration indicators, namely, initial infiltration rate, average infiltration rate, stable infiltration rate, and total infiltration amount, as follows:

Initial infiltration rate $=$ infiltration volume in the initial infiltration period/infiltration time (obtain the average infiltration rate in the first $3 \mathrm{~min}$ ).

Average infiltration rate $=$ infiltration volume at stable infiltration state/time required to reach stable infiltration state.

Stable infiltration rate is the infiltration rate when the infiltration amount per unit time is stable.

The total infiltration volume is the cumulative infiltration volume at stable infiltration.

The reliable and commonly used empirical model Kostiakov and physical model Philip were used to simulate and compare the soil infiltration process of various types of green space.

(1) Kostiakov infiltration model:

$$
f(t)=a t^{-b}
$$

where $f(t)$ is the infiltration rate, $\mathrm{mm} / \mathrm{min}$; $t$ is the infiltration time, min and $a, b$ are the fitting parameters.

(2) Philip infiltration model:

$$
I(t)=A+B t^{-0.5}
$$

where $I(t)$ is the infiltration rate, $\mathrm{mm} / \mathrm{min}$; $t$ is the infiltration time, $\mathrm{min} ; A$ is the stable infiltration rate, $\mathrm{mm} / \mathrm{min}$ and $B$ is the parameters of the model.
IBM SPSS Statistics 22.0 and Origin2017 were used to simulate and map the infiltration process.

\section{RESULT ANALYSIS AND DISCUSSION 4.1 Analysis of the Physicochemical Properties of Soil in Different Open Spaces}

Indicators of soil, such as bulk density, moisture content, porosity, and water, capacity are important indicators of soil characteristics. These parameters can reflect soil performance, including tightness level, pore conditions, water storage, water permeability, and air permeability. In the present study, the cutting ring and drying methods were used to measure the indicators of physicochemical properties in different open spaces. As shown in Tab. 2, evident differences in physicochemical properties of soil are found in different open spaces.

Comparative analysis of soil bulk density: The bulk density of the soil in open green space is $1.16-1.65 \mathrm{~g} / \mathrm{cm}^{3}$ and $75 \%$ soil in open green space soils exhibits $>1.3 \mathrm{~g} / \mathrm{cm}^{3}$ bulk density. Other shared space has the highest bulk density, and the bulk density of square is the lowest. The ranking of the four types of space is as follows: Other shared space $1.36 \mathrm{~g} / \mathrm{cm}^{3}>$ Block $1.34 \mathrm{~g} / \mathrm{cm}^{3}>$ Park $1.31 \mathrm{~g} / \mathrm{cm}^{3}>$ Square $1.23 \mathrm{~g} / \mathrm{cm}^{3}$. Soil bulk density can reflect soil permeability and is related to factors such as soil compaction and texture. The soil with higher bulk density has worse permeability, which can significantly influence water filtration, water storage, and surface runoff [22]. The normal bulk density of soil in green space is approximately $1.3 \mathrm{~g} / \mathrm{cm}^{3}$. The bulk density of soil in various regions is higher than this value. The average soil bulk density of urban green space is $1.39 \mathrm{~g} / \mathrm{cm}^{3}$ in Beijing [2], $1.36 \mathrm{~g} / \mathrm{cm}^{3}$ in Shanghai [19], and $1.48 \mathrm{~g} / \mathrm{cm}^{3}$ in Hefei [4]. The average soil bulk density of green space on both sides of roads in Hong Kong reaches $1.67 \mathrm{~g} / \mathrm{cm}^{3}$ [23]. The soil bulk density in attached green spaces is generally the highest, which is consistent with our measurement result. The increase in soil bulk density is also common in various urban open green spaces. The evident compaction effect is an important reason for the decline of soil permeation rate in green space.

Comparative analysis of soil moisture: Soil moisture content varies in each open space, ranging from $3.83 \%$ to $24.63 \%$. The average moisture content of other shared spaces is the highest. The average moisture contents of other shared space, park, and square are more than $10 \%$, whereas block is only $8.01 \%$. The average moisture content of the four types of open spaces is other shared space $>$ park $>$ square $>$ block. The saturated water capacity of the four types of open spaces ranges from $28.33 \%-48.09 \%$, and park has both maximum and minimum saturated water capacities. The average saturated water capacities are $42.81 \% \pm 2.44 \%, 38.46 \% \pm 6.79 \%, 35.58 \% \pm 3.52 \%$, and $37.08 \% \pm 2.09 \%$ for square, park, other shared space, and block respectively. These values are significantly lower than that of natural forest land [24]. Soil moisture content can influence the various physical, chemical, and biochemical processes of the soil. As the main control factor for energy and water exchange between the soil surface and the atmosphere through evaporation, soil moisture content evidently affects plant growth and runoff regulation. The open spaces have low soil moisture content and water capacity. The majority of vegetation in open space is 
artificially planted with the soil removed from other places, severely affecting soil and low holding capacity.

Comparative analysis of soil porosity: The total porosity of open green space ranges from $25.98 \%$ to $55.74 \%$. The porosity of park is the highest, whereas the other shared space has the lowest porosity. The average porosity is ranked as follows: Park $43.15 \%>$ Square $42.62 \%>$ Block $37.66 \%>$ Other shared space 36.24 . Water movement and storage occur in soil pores, thereby influencing soil permeability and determine surface runoff and runoff time. The total porosity suitable for plant growth is $50 \%-56 \%$ [19]. Green space has low total porosity, which can hinder plant growth and ecological benefits. The number of non-capillary pores and the quality of connectivity can directly influence and reflect the filtration performance of soil. As shown in Tab. 2, the non-capillary porosity of different green spaces ranges from $2.03 \%$ to $18.31 \%$, with an average value of $8.98 \%-14.48 \%$, Square $14.48 \%>$ Block $12.06 \%>$ Park $10.62 \%>$ Other shared space $8.98 \%$. The average porosities of green spaces in Beijing, Shanghai and Hong Kong were 3.71\% - 7.39\%, $3.51 \%-7.76 \%$ and $3.26 \%-20.14 \%$, respectively. Most of these values were lower than the porosity of green space in this study.

Table 2 Physicochemical properties of soil in different green spaces

\begin{tabular}{|c|c|c|c|c|c|}
\hline Parameter & Project & Park & Square & Block & Other shared space \\
\hline Soil bulk density $/ \mathrm{g} / \mathrm{cm}^{3}$ & $\begin{array}{c}\text { Range } \\
\text { Average } \pm S D\end{array}$ & $\begin{array}{l}1.20-1.65 \\
1.31 \pm 0.21\end{array}$ & $\begin{array}{l}1.16-1.29 \\
1.23 \pm 0.09\end{array}$ & $\begin{array}{l}1.21-1.45 \\
1.34 \pm 0.13\end{array}$ & $\begin{array}{c}1.22-1.41 \\
1.36 \pm 0.05\end{array}$ \\
\hline Moisture content / \% & $\begin{array}{c}\text { Range } \\
\text { Average } \pm S D\end{array}$ & $\begin{array}{l}3.83-24.63 \\
11.79 \pm 6.77\end{array}$ & $\begin{array}{l}8.37-17.66 \\
10.02 \pm 6.57\end{array}$ & $\begin{array}{c}4.30-11.51 \\
8.01 \pm 4.42\end{array}$ & $\begin{array}{r}6.81-19.03 \\
14.7 \pm 1.17 \\
\end{array}$ \\
\hline Saturated water capacity / \% & $\begin{array}{c}\text { Range } \\
\text { Average } \pm S D\end{array}$ & $\begin{array}{l}28.33-48.09 \\
38.46 \pm 6.79 \\
\end{array}$ & $\begin{array}{l}40.19-45.02 \\
42.81 \pm 2.44 \\
\end{array}$ & $\begin{array}{l}30.12-38.24 \\
35.58 \pm 3.52 \\
\end{array}$ & $\begin{array}{l}34.92-44.09 \\
37.08 \pm 2.09 \\
\end{array}$ \\
\hline Non-capillary porosity / \% & $\begin{array}{c}\text { Range } \\
\text { Average } \pm S D\end{array}$ & $\begin{array}{l}2.03-16.31 \\
10.62 \pm 2.93 \\
\end{array}$ & $\begin{array}{c}6.35-18.31 \\
14.48 \pm 6.07 \\
\end{array}$ & $\begin{array}{c}7.17-16.52 \\
12.06 \pm 4.57 \\
\end{array}$ & $\begin{array}{l}3.23-14.22 \\
8.98 \pm 5.85 \\
\end{array}$ \\
\hline Total porosity / $\%$ & $\begin{array}{c}\text { Range } \\
\text { Average } \pm S D\end{array}$ & $\begin{array}{l}33.55-51.31 \\
43.15 \pm 5.34\end{array}$ & $\begin{array}{c}39.50-55.74 \\
42.62 \pm 4.42\end{array}$ & $\begin{array}{r}28.41-50.23 \\
37.66 \pm 3.56\end{array}$ & $\begin{array}{c}25.98-41.99 \\
36.24 \pm 3.04\end{array}$ \\
\hline
\end{tabular}

\subsection{Infiltration Process and Characteristics of Soil in Different Green Spaces}

The infiltration characteristic indicators of soil in different open green spaces are measured using the cuttingring method. As shown in Tab. 3, certain differences are found in the infiltration indicators of various types of open green spaces. The initial infiltration rates of park, square, block, and other shared space are 4.79, 5.35, 5.61 and 2.75 $\mathrm{mm} / \mathrm{min}$, respectively. The stable infiltration rates are 3.60 , $2.95,2.75$ and $2.46 \mathrm{~mm} / \mathrm{min}$, respectively. The average infiltration rates are $4.02,3.81,3.60$ and $2.57 \mathrm{~mm} / \mathrm{min}$, respectively. The stable infiltration rate and average infiltration rate of park are significantly larger than those of the other three types of spaces. The initial infiltration rate of block is the largest. However, its stable infiltration rate and average infiltration rate are inferior to those of park and square. Other shared space has the minimum initial infiltration rates, stable infiltration rate, average infiltration rate, and total infiltration capacity. The total infiltration capacities of park, block, and square during the stable permeation time are more than twice those of other shared space, and the initial infiltration rates of square and block are twice that of other shared space.

Table 3 Indicators of soil infiltration characteristics in different open spaces

\begin{tabular}{|c|c|c|c|c|}
\hline Space type & $\begin{array}{c}\text { Initial } \\
\text { infiltration } \\
\text { rate / } \\
\mathrm{mm} / \mathrm{min}\end{array}$ & $\begin{array}{c}\text { Stable } \\
\text { infiltration } \\
\text { rate / } \\
\mathrm{mm} / \mathrm{min}\end{array}$ & $\begin{array}{c}\text { Average } \\
\text { infiltration } \\
\text { rate / } \\
\mathrm{mm} / \mathrm{min}\end{array}$ & $\begin{array}{c}\text { Total } \\
\text { infiltration } \\
\text { capacity / } \\
\mathrm{mm}\end{array}$ \\
\hline Park & 4.79 & 3.60 & 4.02 & 152.77 \\
\hline Square & 5.35 & 2.95 & 3.81 & 144.97 \\
\hline Block & 5.61 & 2.75 & 3.60 & 152.87 \\
\hline $\begin{array}{c}\text { Other shared } \\
\text { space }\end{array}$ & 2.75 & 2.46 & 2.57 & 69.19 \\
\hline
\end{tabular}

As shown in Fig. 1, the soil infiltration rates of different open spaces vary greatly over time, but they all show the same trend of initial infiltration rate $>$ average infiltration rate $>$ stable infiltration rate. This finding is consistent with the results of many related studies $[25,26]$. The reason is inseparable from the three stages of soil infiltration. The infiltration begins at the water wetting stage.

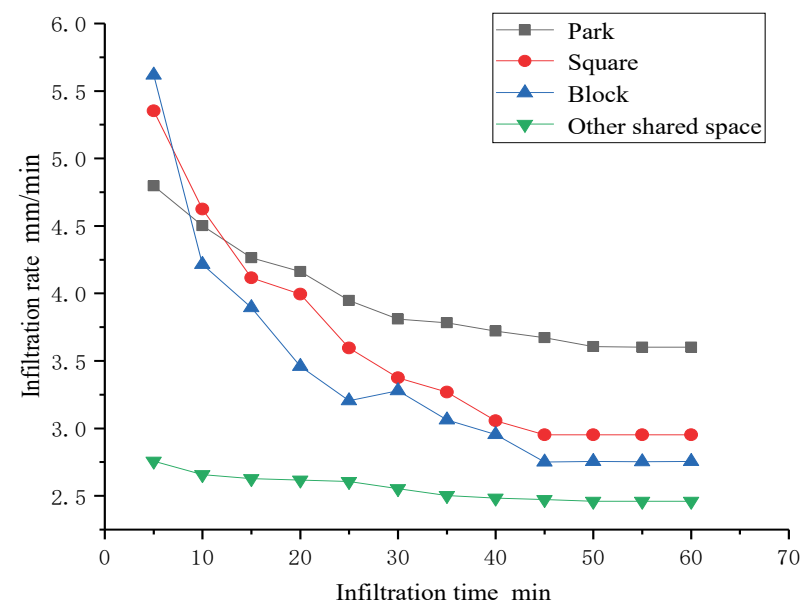

Figure 1 Curves of soil infiltration in different open spaces

Dry soil has great infiltration rate. At the leaking stage, the water moves in pores, and the infiltration rate decreases rapidly; the soil pores have been saturated with water at the soak stage, and the water infiltration gradually slows down to maintain stability. The infiltration rates of park, square, and block are higher during the initial infiltration period, decrease over time, gradually flatten after $40 \mathrm{~min}$ and finally stabilize at a fixed level, that is, the stable infiltration stage is reached. The initial infiltration rates of park, square, and block are significantly higher than those of other shared space and decrease over time. The changes in the infiltration rate of other shared space are relatively smooth, and the initial, stable, and average infiltration rates are significantly smaller than those of the other three types of spaces. Various shared spaces exist in cities, and the soil is miscellaneous filled soil with compact structure and few non-capillary pores, which limit the infiltration of rainwater. 


\subsection{Fitting and Comparative Analysis of Soil Infiltration}

Kostiakov \& Philip models were introduced to Origin 2017 in the form of custom functions, and the measured soil infiltration data of the four types of space were conducted with non-linear curve fitting to obtain the simulation accuracy and the parameters.

In Kostiakov model, $a$ is the infiltration rate in the initial period (the infiltration rate at the end of the first minute), and its value is influenced by various factors, such as soil structure, porosity, and non-capillary porosity [24]. $b$ is a parameter related to soil properties and represents the decrease degree of the infiltration rate over time [27]. As shown in Tab. 4, the fitting parameter $a$ of Kostiakov model is between 2.9925 and 8.7857 at the order of block $>$ square $>$ park $>$ other shared space. This order is consistent with the initial infiltration rate of the four types of space. $b$ of square and block is high, indicating that the infiltration rates of square and block rapidly decrease over time, which is consistent with Fig. 1.

In Philip equation, $A$ is the stable infiltration rate. The value of $A$ of each type of space is substituted to obtain parameter $B$. The value of $B$ ranges from 0.5376 to 3.9892 , which reflects the initial infiltration rate to a certain extent. Other shared spaces have the smallest value of $B$, which is in accordance with the minimum initial infiltration rate of other shared space in Tab. 3.

The determination coefficient $R^{2}$ of regression equations represents the fitting effect of different models on the infiltration process. The larger the value of $R^{2}$, the better the fitting effect. Tab. 4 shows that the Kostiakov model has great determination coefficients, ranging from 0.9479 to 0.9849 . This value is close to the determination coefficients of park and squares that are above 0.98 , and the fitting effect is good. The determination coefficient of the Philip model is between 0.6261 and 0.6765 , showing poor suitability.

The fitting curves of the two infiltration models in Fig. 2 show that the Kostiakov model has a higher coincidence degree from the initial infiltration to the stable infiltration stage. This result is consistent with the values in Tab. 4. The fitting effect of the Kostiakov model is significantly better than that of the Philip model, indicating that the Kostiakov model is more suitable for describing the soil infiltration law in the study area. This finding is consistent with previous study results. The Kostiakov model is an empirical model with a simple infiltration formula and has a high application rate. According to the study of the characteristics of soil infiltration in forest in the Jinsha River and the comparative analysis and simulation of the soil infiltration characteristics of different communities in the forest area of the Tianshan mountain [24, 28], the Kostiakov model has better fitting effect than the Philip model. In the soil permeability study of the five types of urban green spaces in Shenzhen, the Kostiakov empirical formula has good applicability.
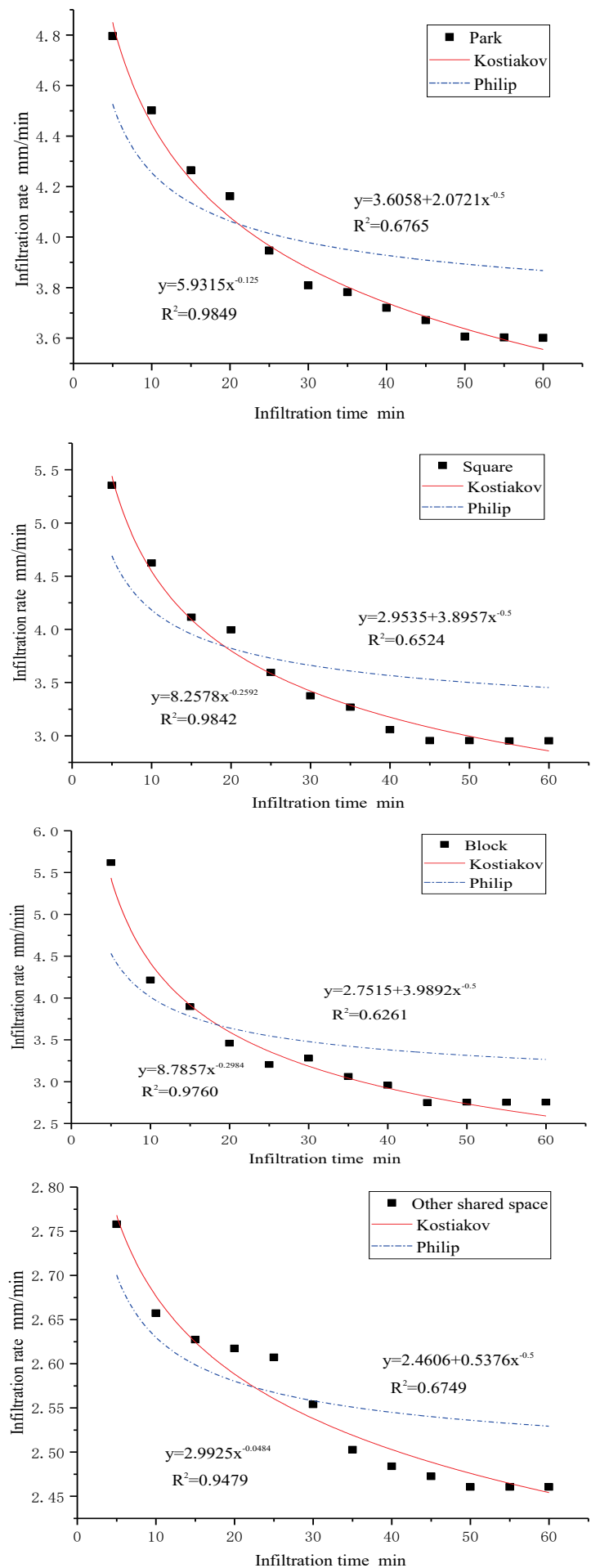

Figure 2 Fitting curves of the soil infiltration models of different green spaces

Table 4 Statistical results of fitting parameters of the infiltration models

\begin{tabular}{|c|c|c|c|c|c|c|c|}
\hline \multirow{2}{*}{ Space type } & & \multicolumn{3}{|c|}{ Kostiakov model $f(t)=a t^{-b}$} & \multicolumn{3}{|c|}{ Philip model $I(t)=A+B t^{-0.5}$} \\
\hline & & $a$ & $b$ & $R^{2}$ & $A$ & $B$ & $R^{2}$ \\
\hline \multirow{2}{*}{ Park } & Fitted value & 5.9315 & 0.1250 & 0.9849 & 3.6058 & 2.0721 & 0.6765 \\
\hline & Error & 0.0859 & 0.0045 & - & - & 0.2841 & - \\
\hline \multirow{2}{*}{ Square } & Fitted value & 8.2578 & 0.2592 & 0.9842 & 2.9535 & 3.8957 & 0.6524 \\
\hline & Error & 0.2363 & 0.0093 & - & - & 0.5830 & - \\
\hline \multirow{2}{*}{ Block } & Fitted value & 8.7857 & 0.2984 & 0.9760 & 2.7515 & 3.9892 & 0.6261 \\
\hline & Error & 0.3445 & 0.0130 & - & - & 0.6563 & - \\
\hline \multirow{2}{*}{ Other shared space } & Fitted value & 2.9925 & 0.0484 & 0.9479 & 2.4606 & 0.5376 & 0.6749 \\
\hline & Error & 0.0334 & 0.0034 & - & - & 0.0706 & - \\
\hline
\end{tabular}

$R^{2}$ is the determination coefficient. 


\subsection{Correlation Analysis of Soil Infiltration Factors}

The SPSS software was used to implement correlation analysis of the direct and indirect factors affecting soil infiltration rates. Tab. 5 shows the negative correlation between soil bulk density and soil infiltration rate.

Table 5 Correlation analysis of soil infiltration rate and influencing factors

\begin{tabular}{|c|c|c|c|c|}
\hline & $\begin{array}{c}\text { Soil bulk } \\
\text { density }\end{array}$ & $\begin{array}{c}\text { Soil moisture } \\
\text { content }\end{array}$ & $\begin{array}{c}\text { Capillary } \\
\text { porosity }\end{array}$ & $\begin{array}{c}\text { Non- } \\
\text { capillary } \\
\text { porosity }\end{array}$ \\
\hline $\begin{array}{c}\text { Initial } \\
\text { infiltration rate }\end{array}$ & -0.550 & $-0.511^{*}$ & -0.608 & $0.296^{*}$ \\
\hline $\begin{array}{c}\text { Stable } \\
\text { infiltration rate }\end{array}$ & -0.368 & -0.546 & 0.296 & 0.579 \\
\hline $\begin{array}{c}\text { Average } \\
\text { infiltration rate }\end{array}$ & -0.619 & -0.501 & -0.282 & 0.091 \\
\hline
\end{tabular}

*means the correlation coefficient is 0.05 significant level

Soil moisture content is negatively correlated with soil infiltration rate and significant negatively correlated with the initial infiltration rate $(p<0.05)$. A large initial soil moisture content leads to a low initial infiltration rate. The soil infiltration rate decreases with increasing moisture content until the stable state is reached. Positive correlation exists between the non-capillary porosity and the soil infiltration rate, and the correlation with the initial infiltration rate reaches a significant level $(p<0.05)$. Capillary porosity and soil infiltration rate show certain positive and negative correlation, but the difference is insignificant. The permeability of soil in different open green spaces in the plot area depends on bulk density, moisture content, and non-capillary porosity.

\section{CONCLUSION}

To determine the characteristics and differences of soil infiltration in urban open green space and to reveal the infiltration process and the coupling relationship between different influencing factors, this study explored the four types of open green spaces, namely, urban park, square, block, and other shared space. Based on the combination of the cutting-ring method and the infiltration model fitting, the effects of soil bulk density, moisture content, and porosity on soil infiltration performance were analyzed. The fitting curves of Kostiakov and Philip infiltration models were established. The following conclusions could be drawn:

(1) The stable infiltration rate of soil in the four types of open spaces is ranked as follows: park $>$ square $>$ block $>$ other shared space. The four types of spaces show the law of initial infiltration rate $>$ average infiltration rate $>$ stable infiltration rate. Some differences exist in the infiltration performance and infiltration process. The initial infiltration rate of park, square, and block first decreases rapidly and then gradually slows down, whereas the infiltration rate of other shared space changes slowly.

(2) The determination coefficient $R^{2}$ fitted by the Kostiakov model is above 0.94 . The model has good applicability to the infiltration process of soil in open green spaces.

(3) Bulk density, moisture content, and non-capillary porosity are the main influencing factors of soil infiltration performance in open spaces. Moisture content and non-capillary porosity show significant correlation with initial permeation rate.

Based on the combination of field measurement and model fitting, this study revealed the differences and laws of soil infiltration in different urban open spaces. The fitting curves of the two infiltration models show differences in applicability, which serve as reference for optimizing sponge green space construction and predicting infiltration process. Given the lack of the monitoring data on the soil infiltration capacity of different vegetation communities in green spaces, the moisture movement, the changes of permeation rate, and the water redistribution of different types of vegetation under rainfall mechanism need further study.

\section{Acknowledgements}

This study was supported by the National Natural Science Foundation of China (31570701); the Natural Science Foundation of Liaoning Province (20170540071); and the scientific research funding project of the Education Department of Liaoning Province (J2019027).

\section{REFERENCES}

[1] Bi, C., Zhang, J. G., Lu, M. Z., \& Zhao, B. (2019). Measurement of service capacity of urban recreational public open space: taking the central urban area of Nanjing as an example. Journal of Nanjing Forestry University (Natural Sciences Edition), 43(04), 117-124.

[2] Dai, Z. Y., Sui, J. X., Xu, X., \& Li, X. Y. (2019). Study on Soil Water Infiltration in Different Urban Green Space in Beijing. Chinese Landscape Architecture, 35 (06), 105-108. https://doi.org/10.19775/j.cla.2019.06.0105

[3] Lin, B. B., Egerer, M. H., Liere, H., Jha, S., Bichier, P., \& Philpott, S. M. (2018). Local-and landscape-scale land cover affects microclimate and water use in urban gardens. Science of the Total Environment, 610, 570-575. https://doi.org/10.1016/j.scitotenv.2017.08.091

[4] Xiong, S. Z. (2018). Study on soil permeability of five kinds of urban green lands in Shenzhen. Grassland and Turf, 38 (03), 67-72+78. https://doi.org/10.13817/j.cnki.cyycp.2018.03.011

[5] Luo, J. M., Meng, J., Yan, W., \& Wang, Y. J. (2016). Water Retention and Influence Factor of Soil in the Urban Green Belt. Chinese Journal of Soil Science, 47 (05), 1113-1118. https://doi.org/10.19336/j.cnki.trtb.2016.05.15

[6] Yang, X., You, X. Y., Ji, M., Pan L. M., Wang, X. D., \& Zhao, L. J. (2011). Soil infiltration model of urban green space and parameter determination. Urban Environment \& Urban Ecology, 24(06), 18-21.

[7] Wu, H. B., Zhou, J. Q., \& Fang, H. L. (2017). Soil water reservoir properties of green belts in the central urban area of Shanghai. Chinese Journal of Applied Ecology, 28(03), 966-974. https://doi.org/10.13287/j.1001-9332.201703.013

[8] Lai, J. \& Ren, L. (2007). Assessing the size dependency of measured hydraulic conductivity using double-ring infiltrometers and numerical simulation. Soil Science Society of America Journal, 71(6), 1667-1675. https://doi.org/10.2136/sssaj2006.0227

[9] Joel, A. \& Messing, I. (2008). Application of two methods to determine hydraulic conductivity with disc permeameters on sloping land. European Journal of Soil Science, 51(1), 93-98. https://doi.org/10.1046/j.1365-2389.2000.00281.x

[10] Singh, R., Panigrahy, N., \& Philip, G. (1999). Modified rainfall simulator in filtrometer for infiltration, runoff and 
erosion studies. Agricultural Water Management, 41(3), 167-175. https://doi.org/10.1016/s0378-3774(99)00020-7

[11] Harden, C. P. \& Scruggs, P. D. (2003). Infiltration on mountain slopes: a comparison of three environments. Geomorphology, 55(1-4), 5-24. https://doi.org/10.1016/S0169-555X(03)00129-6

[12] Minh, T. X., Lei, G., \& Oanh, H. T. T. (2018). Study on the water infiltration and retention of soil after shifting cultivation in Nghe An province, Vietnam. IOP Conference Series: Earth and Environmental Science, 186(3), 12-22. https://doi.org/10.1088/1755-1315/186/3/012022

[13] Santos, K. F. D., Barbosa, F. T., Bertol, I., Werner, R. D. S., Wolschick, N. H., \& Mota, J. M. (2018). Study of soil physical properties and water infiltration rates in different types of land use. Semina: Ciências Agrárias, 39(1), 87-98. https://doi.org/10.5433/1679-0359.2018v39n1p87

[14] Gill, S. E., Handley, J., Ennos, A. R., \& Pauleit, S. (2007). Adapting Cities for Climate Change: The Role of the Green Infrastructure. Built Environment, 33(1), 115-133. https://doi.org/10.2148/benv.33.1.115

[15] Carter, J. G., Handley, J., Butlin, T., \& Gill, S. (2018). Adapting cities to climate change - exploring the flood risk management role of green infrastructure landscapes. Journal of Environmental Planning and Management, 61(9), 15351552. https://doi.org/10.1080/09640568.2017.1355777

[16] Morbidelli, R., Corradini, C., Saltalippi, C., Flammini, A., Dari, J., \& Govindaraju, R. S. (2018). Rainfall infiltration modeling: a review. Water, 10(12), 1873. https://doi.org/10.3390/w10121873

[17] Ma, J. G., Ma, J. W., \& Lu, M. (2016). Investigation on Soil Infiltration of Park Green Space in Kunming. Journal of Southwest Forestry University, 36(03), 111-115.

[18] Wu, H.B., Fang, H.L. \& Peng, H. L. (2016). Soil water reservoir properties and influencing factors of typical newlyestablished green belts of Shanghai Chenshan Botanical Garden, China. Chinese Journal of Applied Ecology, 27(05), 1437-1444. https://doi.org/10.13287/j.1001-9332.201605.005

[19] Wu, H. B. (2018). Study on soil physical properties of green belts in central urban area of shanghai. Soils, 50(01), 155161. https://doi.org/10.13758/j.cnki.tr.2018.01.021

[20] Wu, H. B. \& Fang, H. L. (2015). Research progress on soil infiltration of green space and its importance for municipal ecological security. Chinese Journal of Ecology, 34(03), 894-900. https://doi.org/10.13292/j.1000-4890.2015.0120

[21] Zhang, Y. C. \& Wang, J. P. (2018). Soil Texture and Type of Urban Green Space and Its Influence to Rainwater Infiltration-A Case of Xinxiang City. Chinese Landscape Architecture, 34(09), 100-103.

[22] Zhang, M. X., Liu, W., Zhu, M., Yang L. S., \& Li, R. L. (2019). Patterns and Environmental Controls of Soil Bulk Density in the Mountainous Regions of the Upper Heihe River Basin. Mountain Research, 37(02), 198-205. https://doi.org/10.16089/..cnki.1008-2786.000413

[23] Zhang, H., Mo, L. J., Chen, K. X., Ye, Y. C., Liu, S. S., \& Hong, W. J. (2016). Impact of Thinning on Physio-chemical Properties, Soil microorganism biomass and soil enzyme activities on the season of Hong Kong plantation. Ecology and Environment Sciences, 25(12), 1937-1944. https://doi.org/10.16258/j.cnki.1674-5906.2016.12.007

[24] Aru, S., Chang, S. L., \& Zhang, Y. T. (2019). Comparative analysis and simulation of soil moisture infiltration characteristics in different communities in the forests of Tianshan Mountains. Acta Ecologica Sinica, 39(24), 1-8.

[25]Li, K., Yao, W.Y., Xiao, P.Q., Zhuang, N., Yang, C.X.,\& Zhang, H. (2017). Research Progress on the effect of vegetation on soil infiltration and Surface runoff production. Soil and Water Retention in China, 3, 27-30.

https://doi.org/10.14123/j.cnki.swcc.2017.0058
[26] Liu, J. H., \& Liu, X. L. (2017). Study on Space allocation and service scope of park green land in Jiayuguan. Grassland and Turf, 37(5), 41-46. https://doi.org/10.13817/j.cnki.cyycp.2017.05.007

[27] Zhao, Y. P., Bai, Y. R., Wang, Y. Q., \& Yang, C. X. (2017). Investigating and modeling soil infiltration process with gravel mulch on urban green space. Journal of Northwest A\&F University (Natural Science Edition), 45(07), 66-72. https://doi.org/10.13207/j.cnki.jnwafu.2017.07.009

[28] Liu, Z. Q., Lang, N. J., Peng, M. J., Wen, S. L., Li, T. J., \& Wu, Y. F.(2014). Infiltration characteristics of different forest soils in Jinsha river basin. Bulletin of Soil and Water Conservation, 34(2), 43-47.

https://doi.org/10.13961/j.cnki.stbctb.2014.02.010

\section{Contact information:}

Yu ZHANG, PhD candidate

(Corresponding author)

1) College of Landscape, Northeast Forestry University, China,

2) School of Art \& Design, Dalian Polytechnic University, China,

No.1 Qinggong Yuan, Ganjingzi District, Dalian, Liaoning Province, China

E-mail: zy810112@163.com

Fucun CAO, PhD, Full professor

School of Art \& Design, Dalian Polytechnic University, China,

No.1 Qinggong Yuan, Ganjingzi District, Dalian, Liaoning Province, China

E-mail: cfc1969@sina.com

Leichang HUANG, PhD, Full professor

School of Art \& Design, Dalian Polytechnic University, China,

No.1 Qinggong Yuan, Ganjingzi District, Dalian, Liaoning Province, China

E-mail: baomason@163.com

Yunwei ZHOU, PhD, Full professor

College of Landscape, Northeast Forestry University, China,

26 Hexing Road, Xiangfang district, Harbin, Heilongjiang Province, China

E-mail: boombiubiubiu@126.com

Zhao YANG, Master graduate student

Department of Business, Government and Law, Flinders University, Australia,

Sturt Road, Bedford Park SA 5042, Adelaide, Australia

E-mail: hcf620@163.com 